\title{
Different diffusion-weighted MRI findings in brainstem neuro-Behçet's disease
}

\author{
Sema Yildiz, ${ }^{1}$ Nurefsan Boyaci, ${ }^{1}$ Dilek Sen Dokumaci, ${ }^{1}$ Ahmet Boyaci ${ }^{2}$
}

${ }^{1}$ Department of Radiology, Harran University School of Medicine, Sanliurfa, Turkey ${ }^{2}$ Department of Physical Medicine and Rehabilitation Harran University School of Medicine, Sanliurfa, Turkey

\section{Correspondence to} Nurefsan Boyaci,

drnurefsan@yahoo.com

\section{DESCRIPTION}

A 28-year-old man was admitted with slurred speech and right arm and leg weakness. His medical history revealed repetitive aphthous oral ulcerations. Brain MRI showed lesions on pons extending to bilateral middle cerebellar peduncles (figure 1). Diffusion-weighted imaging (DWI) showed hypointensity in mid-pons with high apparent diffusion coefficient (ADC) value $\left(1.817 \times 10^{-3} \mathrm{~mm}^{2} / \mathrm{s}\right.$; figure $2 \mathrm{~A}$ ) and hyperintensity in left pons with low ADC value $\left(0.66 \times 10^{-3} \mathrm{~mm}^{2} / \mathrm{s}\right)$ compared with the ADC value of lesion-free pons $\left(0.99 \times 10^{-3} \mathrm{~mm}^{2} / \mathrm{s}\right.$; figure 2B).
The patient was diagnosed with Behçet's disease with incipient genital ulcers; brainstem lesions were regarded as acute neuro-Behçet's disease (NBD) lesions. A follow-up MRI at eighth month has shown almost complete resolution of lesions, with small focus in pons and has shown coexistent brainstem and cerebellar atrophy after the steroid therapy. Follow-up DWI showed no abnormality, but a high ADC value $\left(1.22 \times 10^{-3} \mathrm{~mm}^{2} / \mathrm{s}\right)$ was noted in hyperintense lesion on T2-weighted imaging (T2WI) (figure 3).

NBD can be defined as meningoencephalitis with predilection for brainstem, basal ganglia and

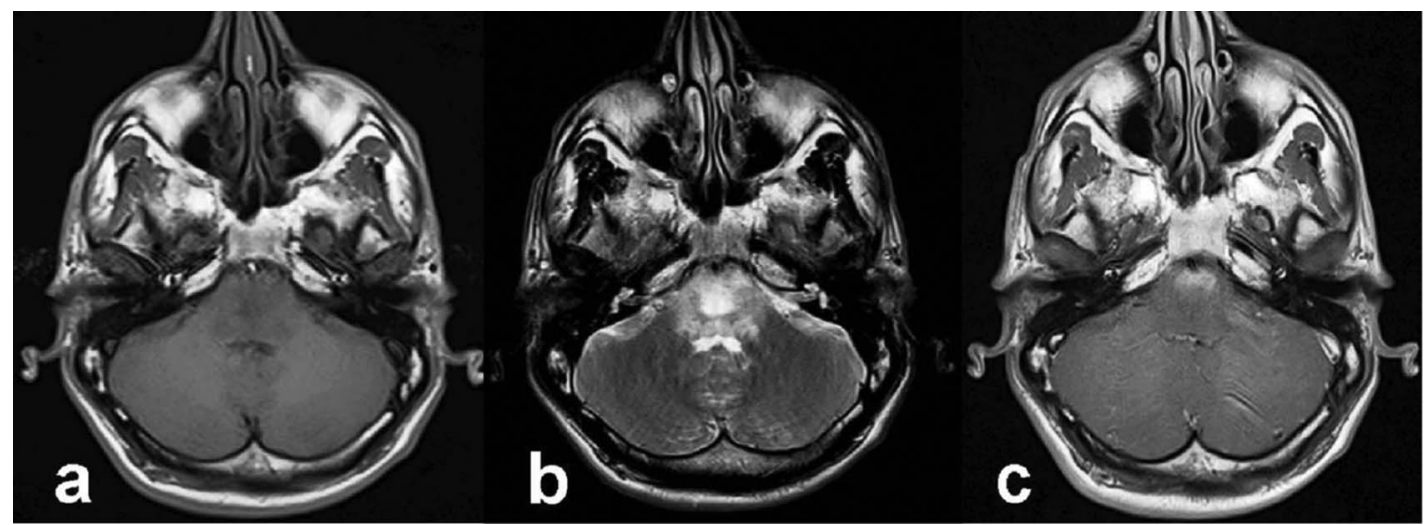

Figure 1 Brain MRI shows lesions in the pons extending to bilateral middle cerebellar peduncles, which are hypointense on T1-weighted imaging (A), hyperintense on T2-weighted imaging (B), with heterogeneous contrast enhancement (C).

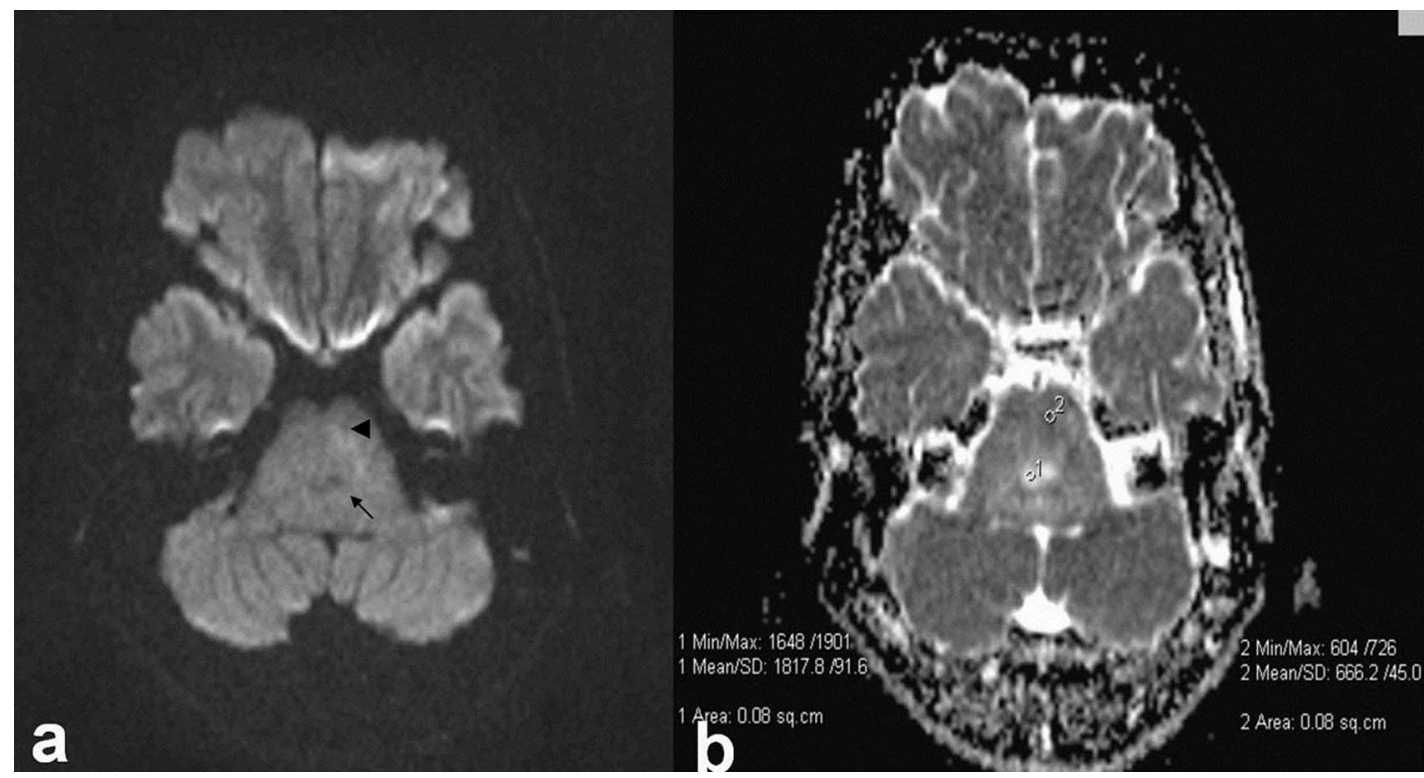

Figure 2 (A) Diffusion-weighted imaging shows low signal intensity in central part of pons (arrow), high signal intensity on left side of the pons (arrowhead). (B) Apparent diffusion coefficient map shows vasogenic oedema in central part of pons (arrow), cytotoxic oedema on left side of the pons (arrowhead). 


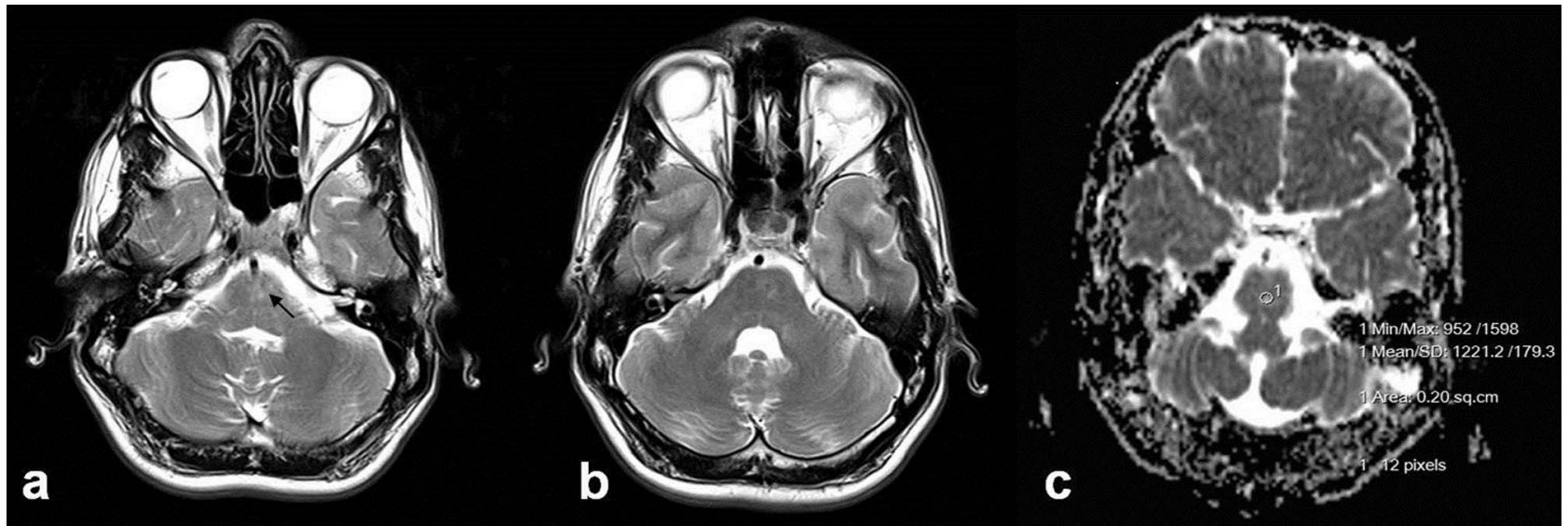

Figure 3 Follow-up T2-weighted imaging (T2WI) shows (A) high signal intensity in the pons (arrow), (B) brain stem and cerebellar atrophy and (C) apparent diffusion coefficient map shows gliosis/demyelination on the of pons.

thalamus, subcortical white matter damage and spinal cord lesions. ${ }^{1}$ Well-known conventional MRI features of acute/subacute parenchymal NBD include hyperintense lesions on T2WI with contrast enhancement on T1-weighted imaging. These lesions tend to resolve or decrease in size in the chronic phase. ${ }^{2}$ The DWI findings in NBD are (A) hyperintensity with ADC values (possibly due to vasogenic oedema and vasculitis) in acute/active disease ${ }^{2}$ and (B) hyperintensity on DWI with decreased ADC value (due to cytotoxic oedema following ischaemic changes caused by vasculitis) in subacute NBD. ${ }^{3}$ Furthermore, chronic lesions may show high ADC values consistent with demyelisation or reactive gliosis. ${ }^{2}$

\section{Competing interests None.}

Patient consent Obtained.

Provenance and peer review Not commissioned; externally peer reviewed.

\section{REFERENCES}

1 Akman-Demir G, Serdaroglu P, Tasci B. Clinical patterns of neurological involvement in Behcet's disease: evaluation of 200 patients. The Neuro-Behcet Study Group. Brain 1999:122:2171-82.

2 Kunimatsu A, Abe 0 , Aoki S, et al. Neuro-Behcet's disease:analysis of apparent diffusion coefficients. Neuroradiology 2003:45:524-7.

3 Shrestha I, Ohshita T, Naka $\mathrm{H}$, et al. Cytotoxic edema in neuro-Behcet's disease? Intern Med 2008:47:2073-6.

\section{Learning points}

- Neuro-Behçet's disease (NBD), is one of the most devastating manifestations of the Behçet's disease.

- Diffusion-weighted imaging (DWI) might help in differential diagnosis of acute brainstem NBD lesions with revealing the vasogenic oedema.

- It is important to know the possibility of other DWI findings in NBD.

Copyright 2013 BMJ Publishing Group. All rights reserved. For permission to reuse any of this content visit http://group.bmj.com/group/rights-licensing/permissions.

BMJ Case Report Fellows may re-use this article for personal use and teaching without any further permission.

Become a Fellow of BMJ Case Reports today and you can:

- Submit as many cases as you like

- Enjoy fast sympathetic peer review and rapid publication of accepted articles

- Access all the published articles

- Re-use any of the published material for personal use and teaching without further permission

For information on Institutional Fellowships contact consortiasales@bmjgroup.com

Visit casereports.bmj.com for more articles like this and to become a Fellow 